\title{
Nanocomposites in food packaging applications and their risk assessment for health
}

\author{
Zohreh Honarvar $^{1}$, Zahra Hadian², Morteza Mashayekh ${ }^{3}$
}

\author{
${ }^{1}$ Student's Research Committee, National Nutrition and Food Technology Research Institute, Shahid Beheshti \\ University of Medical Sciences, Tehran, Iran \\ ${ }^{2}$ Ph.D. of Food Technology, Assistant Professor of Food Technology, National Nutrition and Food Technology \\ Research Institute, Shahid Beheshti University of Medical Sciences, Tehran, Iran \\ ${ }^{3}$ Assistant Professor of Food Technology, School of Nutrition and Food Technology, Shahid Beheshti University of \\ Medical Sciences, Tehran, Iran
}

Type of article: Review article

\begin{abstract}
Nanotechnology has shown many advantages in different fields. As the uses of nanotechnology have progressed, it has been found to be a promising technology for the food packaging industry in the global market. It has proven capabilities that are valuable in packaging foods, including improved barriers; mechanical, thermal, and biodegradable properties; and applications in active and intelligent food packaging. Examples of the latter are anti-microbial agents and nanosensors, respectively. However, the use of nanocomposites in food packaging might be challenging due to the reduced particle size of nanomaterials and the fact that the chemical and physical characteristics of such tiny materials may be quite different from those of their macro-scale counterparts. In order to discuss the potential risks of nanoparticles for consumers, in addition to the quantification of data, a thorough investigation of their characteristics is required. Migration studies must be conducted to determine the amounts of nanomaterials released into the food matrices. In this article, different applications of nanocomposites in food packaging, migration issues, analyzing techniques, and the main concerns about their usage are discussed briefly.
\end{abstract}

Keywords: Nanocomposite; Food; Packaging: Risk assessment

\section{Introduction}

Nanotechnology is the science of engineering materials that have at least one dimension at the nanometer scale (1100 nanometers) (1). By the use of nanotechnology, we can make structures with new characteristics that are attributable to their nanometer dimensions (2). One of the fastest growing fields in nanotechnology is nanocomposite food packaging, which is a good alternative for conventional packaging (3). Usually, composites are composed of a polymer matrix or a continuous phase and a discontinuous phase or filler (4). Nanocomposites are made by the incorporation of nanofillers that have nano-scale lengths in at least one dimension. In the last few decades, the use of synthetic polymers in food packaging has increased significantly because they are versatile, inexpensive, easy to process, and lightweight (5). However, plastic polymers are not biodegradable, so they cause environmental problems because it can take hundreds of years for them to be completely degraded. Since these polymers cause environmental pollution, researchers have been trying to develop new packaging materials that degrade more quickly (6-8). Biopolymers originate from natural polymers, such as polysaccharides and proteins, and they have attracted widespread attention over the last decades because they are biodegradable. Unfortunately, there are some restrictions on the use of biodegradable or natural polymers in food packaging since they can be poor barriers and have adverse mechanical properties (9), making them unsuitable for packaging foods. Obviously, in order to increase the shelf life of food, packaging must have low permeability to gases, such as oxygen and water vapor. However, biopolymers are not good barriers to water vapor because of their hydrophilic nature.

\section{Corresponding author:}

Assistant Professor Dr. Zahra Hadian, National Nutrition and Food Technology Research Institute, Shahid Beheshti University of Medical Sciences, Tehran, Iran.

Tel: +98.2122376473, Fax: +98.2122376467, E-mail: z_hadian@sbmu.ac.ir Received: January 03, 2016, Accepted: May 08, 2016, Published: June 2016 iThenticate screening: March 30, 2016, English editing: May 17, 2016, Quality control: June 02, 2016

(C) 2016 The Authors. This is an open access article under the terms of the Creative Commons Attribution-NonCommercialNoDerivs License, which permits use and distribution in any medium, provided the original work is properly cited, the use is non-commercial and no modifications or adaptations are made. 
Diverse methods can be used to improve the barrier properties of natural polymers, including the use of polymer blends, high-barrier coating materials, and multi-layered films that contain a high-barrier film (5). In addition to these strategies, a novel technique for this purpose is the use of nanocomposites in food packaging. Nanocomposites improve barrier properties and have a positive impact on the thermal and mechanical characteristics of the packaging material (10). However, the main concern about applying nanotechnology in food packaging is related to the tiny sizes of the particles of nanomaterial, which can cause them to have different chemical and physical properties than their macroscale chemical counterparts (3), giving them the potential for causing health problems. In this article, first, we explain briefly the different potential applications of nanocomposites in food packaging. Second, we introduce techniques for analyzing them. Third, we discuss the important concerns that nanocomposites may potentially be hazardous materials; which would preclude their use in packaging food.

\section{Discussion}

\subsection{Important nanoparticles}

To date, many nanoparticles have been identified as fillers for making polymer nanocomposites to improve their packaging performances (Table 1) (11). Among them, clays and silicates have attracted significant attention due to their layered structures. This is because of they are abundant, inexpensive, easy to process, and provide considerable enhancements (12). There are three main polymer-clay morphologies, i.e., tactoid (or phase separated), intercalated, and exfoliated (13). In the tactoid structure, which usually occurs in microcomposites, the polymer chains and the clay gallery are immiscible because they have poor affinity for each other. Nanocomposite structures do not display this morphology (14). In ideal polymer-clay nanocomposites, high affinity would exist between the polymer and clay, leading to exfoliated structures in which polymer chains penetrate into the interlayer space of the clay, making single sheets. If the clay shows a moderate affinity for the polymer, the results would be intercalated structures (5). In the literature, there are reports of other particle fillers being used, including silver, zinc oxide, titanium dioxide, carbon nanotubes, graphene nanoplates, copper, and copper oxides. It is reported that graphene nanoplates (GNPs) are able to form nanocomposites with improved heat resistance and barrier properties, making them a great option for food-packaging applications (15). Carbon nanotubes (CNTs) are another type of carbon-based nanoparticles that have good electrical and mechanical characteristics. However, their use has been hindered, mainly due to their high cost and the difficulty in processing dispersions (5). Copper, copper oxide, titanium dioxide, zinc oxide, and silver have been used mainly for their anti-microbial properties (16).

Table 1. Types and characteristics of nanofillers (11)

\begin{tabular}{|c|c|c|c|}
\hline Type of Nanofiller & Morphology/Structure & Typical dimensions* & Density \\
\hline $\begin{array}{l}\text { Montmorillonite } \\
\text { (MMT) }\end{array}$ & Platelets & $\begin{array}{l}\mathrm{D}: 100-500 \mathrm{~nm}, \mathrm{~T}: \sim \\
1 \mathrm{~nm}^{\mathrm{a}}\end{array}$ & $\sim 2.6 \mathrm{~g} \mathrm{~cm}^{-3}$ \\
\hline $\begin{array}{l}\text { Layered double } \\
\text { hydroxide (LDH) }\end{array}$ & Platelets with distinct hexagonal shape & $\begin{array}{l}\text { D: } 50 \text {-few hundred nm, } \\
\text { T: } \sim 0.5 \mathrm{~nm}^{\mathrm{a}}\end{array}$ & $1.5 \mathrm{~g} \mathrm{~cm}^{-3}$ \\
\hline $\begin{array}{l}\text { Carbon nanotubes } \\
\text { (CNT) }\end{array}$ & $\begin{array}{l}\text { Tubular, seamless cylinder of graphene } \\
\text { sheet }\end{array}$ & $\begin{array}{l}\text { L: up to tens of } \mu \mathrm{m}, \mathrm{D}: \\
\sim 1 / 5 / 20 \mathrm{~nm}^{\mathrm{b}}\end{array}$ & $\begin{array}{l}1.3-1.5 / 1.5 / 1.8- \\
2.0 \mathrm{~g} \mathrm{~cm}^{-3 \mathrm{~b}}\end{array}$ \\
\hline $\begin{array}{l}\text { Cellulose nanowhiskers } \\
\text { (CNW) }\end{array}$ & Rod-like & $\begin{array}{l}\mathrm{L}: 100 \mathrm{~nm}-\text { few } \mu \mathrm{m}, \mathrm{D}: \\
2-10 \mathrm{~nm}\end{array}$ & $\sim 1.6 \mathrm{~g} \mathrm{~cm}^{-3}$ \\
\hline $\begin{array}{l}\text { Microfibrillated } \\
\text { cellulose (MFC) }\end{array}$ & $\begin{array}{l}\text { Highly fibrous network consisting of } \\
\text { bundles of nanofibrils }\end{array}$ & $\begin{array}{l}\text { L: few } \mu \mathrm{m}, \mathrm{D}: 10-100 \\
\mathrm{~nm}\end{array}$ & $\sim 1.6 \mathrm{~g} \mathrm{~cm}^{-3}$ \\
\hline Bacterial cellulose (BS) & $\begin{array}{l}\text { Ribbon-shaped nanofibers }{ }^{\mathrm{c}} \text { forming a } \\
\text { highly fibrous network }\end{array}$ & $\begin{array}{l}\mathrm{L}: \text { few } \mu \mathrm{m}, \mathrm{W}: 50-150 \\
\mathrm{~nm}, \mathrm{~T}: 5-10 \mathrm{~nm}\end{array}$ & $\sim 1.6 \mathrm{~g} \mathrm{~cm}^{-3}$ \\
\hline Chitin whiskers (CHW) & Slender rods & $\begin{array}{l}\text { L: } 50-650 \mathrm{~nm}^{\mathrm{d}}, \mathrm{D}: 4-80 \\
\mathrm{~nm}^{\mathrm{d}}\end{array}$ & $\sim 1.5 \mathrm{~g} \mathrm{~cm}^{-3}$ \\
\hline $\begin{array}{l}\text { Starch nanocrystals } \\
\text { (SNC) }\end{array}$ & $\begin{array}{l}\text { Platelet-like Nanoparticles; often } \\
\text { forming few } \mu \mathrm{m} \text { size aggregates }\end{array}$ & $\begin{array}{l}\mathrm{L}: 20-150 \mathrm{~nm}^{\mathrm{d}}, \mathrm{W}: 15- \\
30 \mathrm{~nm} \cdot \mathrm{T} 6-8 \mathrm{~nm}\end{array}$ & $\sim 1.55 \mathrm{~g} \mathrm{~cm}^{-3}$ \\
\hline
\end{tabular}

L: length; w: width; T: thickness; D: diameter; a: thickness of a single platelet; b: for single-, double- and multiwalled CNTs, respectively; c: aggregates of individual nanofibrils; d: depending on raw material's origin

\subsection{Nanocomposites as degradable improved packaging}

Currently, there is significant interest in developing different packaging materials because of the increasing demand for foods with minimum processing and longer shelf life. Obviously, such new packaging materials must have excellent barrier properties to prevent the migration of oxygen, carbon dioxide, water vapor, and flavor compounds. 
This will have a major influence on the shelf life of fresh and processed foods (5). In the case of using biopolymers, lowering water vapor permeability is especially important due to their hydrophilic nature. However, by the aid of nanocomposite technology, this inherent defect of biopolymer-based packaging materials can be conquered. In many cases, it has been reported that the barrier properties can be improved by about $50 \%$ compared to the properties of the neat polymer (5).This is because of the creation of a maze structure results in a tortuous path for gases and other molecules, thereby reducing their permeation rate (17). Studies have indicated that incorporating nanocomposites in food packaging materials results in better mechanical and thermal behavior of the packaging $(9,18,19)$. For instance, researchers have reported that engineered nanocomposites of biopolymer-layered silicate have noticeably enhanced physical properties, such as higher tensile strength, enhanced thermal stability, and better gas barrier properties $(14,18,20-23)$. By using nanocomposites, the food packaging can better tolerate thermal stress of food processing, shipping, and storage (18). Although traditional composite structures may have large amounts of filler (approximately $60 \%$ by volume), nanocomposites usually represent significant changes in properties at quite low loads, i.e., less than $2 \%$ volume. It is also suggested that, for achieving the best effects of the final nanocomposites, around $5 \mathrm{wt} \%$ of fillers is generally desirable (5). There is adequate evidence proving other benefits of nanocomposite food packaging, e.g., improved stability of sensory properties, such as flavor, better maintenance of color and texture, increased product stability through the food chain, and less spoilage (9). Biopolymers can be derived from plant materials as well as animal and microbial products, such as polyhydroxybutyrate (5). Among these biopolymers, starch $(10,18,24,25)$, cellulose, and their derivatives $(12,26,27)$, as well as proteins $(21,28$ $33)$, have been used extensively by many researchers to make bio-based nanocomposites. The most-reported biodegradable nanocomposite is starch-clay, which has been investigated for several applications including food packaging $(10,24,25,34-37)$.

\subsection{Nanocomposites in active packaging}

Some nanofillers, such as silver, zinc oxide, and magnesium oxide, have antimicrobial or antioxidant activities. Incorporation of these nanofillers in polymer or biopolymer matrices leads to an inhibiting or retarding effect on the growth of microorganisms, thereby reducing food spoilage (3). The main goal of active packaging systems is extending the product's shelf life. They can also be designed to improve food quality and safety and finally result in less food waste (38). Anti-microbial nanocomposite films are worthwhile because of their anti-microbial properties caused by natural anti-microbial agents and because of their suitable structural integrity, which results from the barrier properties created by the nanocomposite matrix (39). Nanoscale materials have a higher surface-to-volume ratio than their microscale counterparts, and, therefore, they are able to attach to a vast number of biological molecules, which enhances their efficiency (40). Previous reports have identified potential applications of nanocomposites as growth inhibitors (41), bacteriocides (24), and antibiotic carriers (42). In addition to the application of nanocomposites as packaging materials, they also can be used as delivery systems by helping the migration of functional additives, such as minerals, probiotics, and vitamins into the food (43). These controlledreleased packagings are another example of a nanomaterial application in active packaging. Many anti-microbial nanocomposites used for food packaging are made from silver, which has an intense toxicity to a large variety of microorganisms (44). Authors have suggested different mechanisms for the anti-microbial activity of silver nanoparticles, such as increasing cell permeability through the attachment to the cell surface and making pits in the membranes (45), damaging DNA followed by nanoparticle penetration inside bacterial cell (46), and the release of $\mathrm{Ag}+(47)$. Active nanocomposites are advanced alternatives to conventional active plastic technologies or active sachets for the extension of the quality and safety of packaged food products. The term 'active nanocomposite' generally refers to a plastic composite (i.e., a polymer blend) that contains an active, nanostructured material that confers an activity on the plastic matrix (11). At least one of the dimensions of the active nanostructured material must be less than $100 \mathrm{~nm}$ in size. Nanoclays can be used as carriers for the active agent. The efficacy of the active agent is enhanced because it is highly dispersed in the polymeric matrix and, hence, exposed more efficiently to the substance on which it is required to act.

\subsection{Nanocomposites in intelligent packaging}

Intelligent packagings are able to communicate with the consumers and give information about the product condition through the food chain. These packagings can monitor, trace, or record outer or inner changes that are occurring in the product or its environment (3). By applying reactive components in the form of nanoparticles and making so-called nanosensors, the packaging will be able to respond to environmental changes, such as temperature, the presence of oxygen, deteriorated products, and microbial contamination (48). Through the incorporation of nanosensors into food packaging, detection of certain chemical compounds, pathogens, and toxins in food would be possible. This also fulfills the need for inexact expiration dates, which, in many cases, are not suitable for the 
products due to false estimation of product condition during storage. So they provide real-time status of the food's freshness (49). These sensors have many advantages over the costly and time-consuming conventional detection methods, such as High-performance liquid chromatography (HPLC). This includes their speed, high-throughput detection, ease of operation, cost effectiveness, and decreased power requirements (50).

\subsection{Analyzing techniques of nanomaterials}

Discussing the potential risks of nanoparticles for consumers requires thorough insight about their characteristics (3). For the characterization of nanocomposite structures, aspects that are more likely to be considered are particle dispersion, changes in the mass matrix, and the type of particle-polymer interface (5). Detecting the migration of nanomaterial into food matrices requires more sensitive analytical techniques due to the complexity of the nanomaterials and their representing only a very small portion of the bulk food. Detection of this material in complex matrices, such as food, requires combined methodologies, since no individual technique can give all the detailed information. Microscopic, spectroscopic, and quantitative analytical techniques are all useful for this purpose. Transmission electron microscopy (TEM), scanning electron microscopy (SEM), and atomic force microscopy (AFM) are good examples of microscopic methods, each of which has its own advantages and disadvantages. By these methods, nanoparticles' general features, such as size, shape, structure, dispersion, and coagulation state, are accessible. However, these techniques usually are destructive, meaning that verification tests for a better analysis are not feasible on the same sample (3). Spectroscopic techniques, such as X-ray diffraction (XRD) and UV-vis spectroscopy, can be used for characterization and analysis of nanomaterial as well. XRD, both wide angle (WAXS) and small angle (SAXS), are the conventional methods that are used to examine nanocomposite structures (5). Elemental composition or the crystalline arrangement of nanomaterials, both in natural and engineered form, can be investigated by the XRD technique (3). Despite microscopic methods, this technique is not destructive, and there is no need for difficult sample pretreatment. These attributes contribute to its extensive application in the characterization of materials (3). Different nanocomposite formations, such as intercalation, exfoliation, and dispersion, conventionally have been studied by XRD (14). The XRD technique traditionally has been used especially for characterizing montmorillonite exfoliation in polymer materials used in packaging applications (51). The supporting method, UV-vis spectroscopy, has been used extensively due to its cost effectiveness and ease of operation. This technique confers information about the presence of nanoparticles and their characterization (3). Nanomaterial quantitation in food packaging applications also is a vital issue because of safety concerns. For this purpose, migrated nanomaterial can be probed through inductively coupled plasma mass spectrometry (ICP-MS), inductively coupled plasma atomic emission spectrometry (ICP-AES), and inductively coupled plasma optical emission spectrometry (ICP-OES), which are three important techniques for quantification and elemental analyses (3). The advantages of these methods include their high selectivity, sensitivity, and accuracy. Using these methods, nanoparticles can be detected in amounts as low as 0.1-10 ppm (3). Introducing nanomaterial into the ICP, a beam of gaseous ions is produced by the atoms of the analyte in the plasma, resulting in an individual pulse measured by the detector, which appears as a peak on the graph (52). Prior to injecting the sample, a digestion process is required because the presence of food components could impede good atomization of the sample (3). An alternative approach to ICP is atomic absorption spectrometry (AAS) for the detection of nanomaterial. In many cases, AAS is used for the quantitative determination of chemical elements within samples, such as food, by measuring the absorption of optical radiation (light) by free atoms in the gaseous state. However, analysis of more than one element is not possible by AAS (53).

\subsection{Nanomaterial migration into food matrix}

One of the critical issues in food packaging is migration. Migration is the unintentional transfer of packaging materials into the food. This problem may influence the food's safety and, subsequently, consumers' health (54). It also can cause undesirable organoleptic changes in the food that is in contact with the packaging. For example, migration of TiO2 into lipid matrix results in rancidity (55). Nevertheless, in some active packaging, nanomaterials are intended to be released deliberately. Performing migration tests under controlled conditions is essential for evaluating the possibility of the nanomaterials' incorporation into food packaging and also assessing the associated safety problems. The analysis condition depends on the type of food matrix or food simulant being tested (3). Different factors impact the migration of nanomaterials into foodstuffs. These factors can be ascribed to the nanoparticles' properties (e.g., concentration, particle size, molecular weight, solubility, and diffusivity in the polymer), environmental conditions (temperature, mechanical stress), food condition ( $\mathrm{pH}$ value, composition), packaging characteristics (polymer structure and viscosity), and contact time (3). For instance, higher temperatures and lower $\mathrm{pH}$ values increase the solubility of metal nanomaterials in aqueous solution, leading to an increase in their migration (56). Low molecular weight polymers that have more free volume accelerate the migration rate and 
nanoparticles' diffusivity (57). There also is an inverse relationship between the migration rate of a system and the size of the nanoparticles (38). If the nature of the food is compatible with the type of packaging, the food itself may be absorbed into the polymer matrix, enlarging the gaps between the polymer chains, thereby increasing the migration rate (3). For example, fats have high affinity for polyethylene (PE) and polypropylene (PP), so they may be absorbed by the packaging and cause an increase in plastic mobility and higher migration rates (3). The preservation method of foods also is important and can affect nanoparticles' migration. It has been reported that microwave heating causes structural modification of the packaging, thereby speeding up the migration of silver ions (52). High surface-to-volume ratios in nanomaterials induce an active surface chemistry followed by probably unwanted chemical reactions. This would be troublesome if their presence in the packaging enhances the formation of unforeseen reaction by-products during processing (58). Nanoparticles also can impact the migration of other packaging constituents, either speeding up or slowing down their migration. To perform migration analysis, the best approach is to use actual food matrices. However, it would be very tedious and difficult to directly estimate the amount of migration into real food matrices due to complex composition of foodstuffs. As a solution to this problem, using natural food stimulants has become an alternative method to measure the specific and overall migration of different packaging substances into foods (59). The amount and rate of mass transport in the selected food stimulants should be similar to those that occur in the food matrix (60).

\subsection{Concerns about nanocomposite packaging}

The most challenging concern about the use of nanoparticles pertains to their reduced particle size, because the chemical and physical characteristics of such tiny materials may be quite different from their macro scale counterparts (3). This implies that issues concerning their toxicity may be different based on their very small sizes (61). This is a very serious problem, because GRAS (generally recognized as safe) decisions probably have been made without any consideration of the size or the related safety evaluations (3). It has been reported that some nanomaterials are potentially harmful to human health. However, there is still insufficient proof concerning whether this is attributable to any kind of nanomaterial applications, especially in the food industry (3). Before confirming the safety of nanomaterials, it has been recommended by the Institute of Food Science and Technology (IFST) that nanomaterial be treated as potentially dangerous materials in order to lessen their possible adverse effects on human health. One of the responsibilities of the Food and Drug Administration (FDA) is to prove the safety of nanoscale products (62). The FDA foundation, for nano-based products are being assessed case-by-case according approved standard. Nevertheless, since there is no labeling prerequisites for such products that state whether nanotechnology has been used in their production, it would be difficult for the FDA to evaluate their safety (63). Present legislation considers that there is no difference between so-called nano-produced materials and those made by ordinary manufacturing approaches. As a result, nano-based material for packaging are not evaluated as new chemicals, and, thus, specific or overall migration limits into food that is in contact with nanomaterials have not been defined (59). Regulating principles about migration limits of different plastics into food matrices are applicable for nanoparticles. Even so, this would not fulfill the increasing for food safety due to differences in the physicochemical characteristics of nano and macro-scale components, which cause them to exhibit different safe limits for their migrations (3). JenYi Huang reported that, currently, there are no internationally agreed-to research protocols or standards concerning nanomaterials (3).

\section{Conclusions}

In food packaging, the use of biodegradable or natural polymers is restricted because of their poor barrier and mechanical properties. By incorporation of even low percentages of nanofillers, such as clay, into these biopolymers, a considerable improvement in general performance can be achieved. This includes mechanical, thermal, and barrier properties. Moreover, nanoparticles could impart as their active or intelligent properties to food packaging so that they can preserve the food against external factors and increase the food's stability through antimicrobial properties and/or responding to environmental changes. In spite of several advantages of nanomaterials, their use in food packaging may cause safety problems to human health since they exhibit different physicochemical properties from their macro-scale chemical counterparts. For studying the effect of nanoparticles on human health, more research is needed and identification, characterization, and quantification of the nanoparticles are prerequisite steps. Migration possibilities and safety control of the nano-packaged foods also are crucial. Unfortunately, present legislation does not distinguish nanotechnology-produced materials from those made by ordinary manufacturing approaches. 


\section{Acknowledgments:}

The authors thank the staff at the National Nutrition and Food Technology Research Institute, Shahid Beheshti University of Medical Sciences for their incredible support.

\section{Conflict of Interest:}

There is no conflict of interest to be declared.

Authors' contributions:

All authors contributed to this project and article equally. All authors read and approved the final manuscript.

\section{References:}

1) Tiede K, Boxall AB, Tear SP, Lewis J, David H, Hassellov M. Detection and characterization of engineered nanoparticles in food and the environment. Food Addit Contam Part A Chem Anal Control Expo Risk Assess. 2008; 25(7): 795-821. doi: 10.1080/02652030802007553. PMID: 18569000.

2) Roco MC. Nanotechnology: convergence with modern biology and medicine. Curr Opin Biotechnol. 2003; 14(3): 337-46. doi: 10.1016/S0958-1669(03)00068-5. PMID: 12849790.

3) Huang JY, Li X, Zhou W. Safety assessment of nanocomposite for food packaging application. Trends in Food Science \& Technology. 2015; 45(2): 187-99. doi: 10.1016/j.tifs.2015.07.002.

4) Matthews FL, Rawlings RD. Composite materials: engineering and science: Elsevier; 1999.

5) Arora A, Padua GW. Review: nanocomposites in food packaging. J Food Sci. 2010; 75(1): 43-9. doi: 10.1111/j.1750-3841.2009.01456.x. PMID: 20492194.

6) Aminabhavi TM, Balundgi RH, Cassidy PE. A review on biodegradable plastics. Polymer-Plastics Technology and Engineering. 1990; 29(3): 235-62. doi: 10.1080/03602559008049843.

7) Crosby NT. Food packaging materials. Aspects of analysis and migration of contaminants: Applied Science Publishers Ltd. 1981; ISBN 0-85334-926-6.

8) Doi Y. Microbial polyesters. VCH Publishers. 1990; 156.

9) Sorrentino A, Gorrasi G, Vittoria V. Potential perspectives of bio-nanocomposites for food packaging applications. Trends in Food Science \& Technology. 2007; 18(2): 84-95. doi: 10.1016/j.tifs.2006.09.004.

10) Avella M, De Vlieger JJ, Errico ME, Fischer S, Vacca P, Volpe MG. Biodegradable starch/clay nanocomposite films for food packaging applications. Food chemistry. 2005; 93(3): 467-74. doi: 10.1016/j.foodchem.2004.10.024.

11) Yam KL, Lee DS. Emerging food packaging technologies, Principles and practice. Elsevier. 2012; doi: $10.1533 / 9780857095664$.

12) Azeredo H, Mattoso LHC, Wood D, Williams TG, Avena - Bustillos RJ, McHugh TH. Nanocomposite edible films from mango puree reinforced with cellulose nanofibers. Journal of food science. 2009; 74(5): 31-5. doi: 10.1111/j.1750-3841.2009.01186.x. PMID: 19646052.

13) McGlashan SA, Halley PJ. Preparation and characterisation of biodegradable starch - based nanocomposite materials. Polymer International. 2003; 52(11): 1767-73. doi: 10.1002/pi.1287.

14) Alexandre M, Dubois P. Polymer-layered silicate nanocomposites: preparation, properties and uses of a new class of materials. Materials Science and Engineering: R: Reports. 2000; 28(1): 1-63. doi: 10.1016/S0927-796X(00)00012-7. doi: 10.1533/9780857095664.

15) Ramanathan T, Abdala A, Stankovich S, Dikin D, Herrera-Alonso M, Piner R, et al. Functionalized graphene sheets for polymer nanocomposites. Nature nanotechnology. 2008; 3(6): 327-31. doi: 10.1038/nnano.2008.96.

16) Duncan TV. Applications of nanotechnology in food packaging and food safety: Barrier materials, antimicrobials and sensors. J Colloid Interface Sci. 2011; 363(1): 1-24. doi: 10.1016/j.jcis.2011.07.017. PMID: 21824625.

17) Demetrakakes P. Nanocomposites raise barriers, but also face them: Clay-based additives increase the barrier qualities of plastics, but obstacles to commercialization must be overcome. Nanocomposite Materials. 2002.

18) Ray SS, Okamoto M. Polymer/layered silicate nanocomposites: a review from preparation to processing. Progress in polymer science. 2003; 28(11): 1539-641. doi: 10.1016/j.progpolymsci.2003.08.002.

19) Ray S, Quek SY, Easteal A, Chen XD. The potential use of polymer-clay nanocomposites in food packaging. International Journal of Food Engineering. 2006; 2(4): 1556-3758. doi: 10.2202/15563758.1149 . 
20) Ray SS, Bousmina M. Biodegradable polymers and their layered silicate nanocomposites: in greening the 21 st century materials world. Progress in materials science. 2005; 50(8): 962-1079. doi: 10.1016/j.pmatsci.2005.05.002.

21) Rhim JW, Lee JH, Kwak HS. Mechanical and water barrier properties of soy protein and clay mineral composite films. Food Science and Biotechnology. 2005; 14(1): 112-6.

22) Rhim JW, Lee JH, Hong SI. Increase in water resistance of paperboard by coating with poly (lactide). Packaging Technology and Science. 2007; 20(6): 393-402. doi: 10.1002/pts.767.

23) Zhao R, Torley P, Halley PJ. Emerging biodegradable materials: starch-and protein-based bionanocomposites. Journal of Materials Science. 2008; 43(9): 3058-71. doi: 10.1007/s10853-007-2434-8.

24) Huang J, He C, Liu $\mathrm{X}$, $\mathrm{Xu}$ J, Tay CS, Chow SY. Organic-inorganic nanocomposites from cubic silsesquioxane epoxides: direct characterization of interphase, and thermomechanical properties. Polymer. 2005; 46(18): 7018-27. doi: 10.1016/j.polymer.2005.05.150.

25) Cyras VP, Manfredi LB, Ton That MT, Vázquez A. Physical and mechanical properties of thermoplastic starch/montmorillonite nanocomposite films. Carbohydrate Polymers. 2008; 73(1): 55-63. doi: 10.1016/j.carbpol.2007.11.014.

26) Burdock GA. Safety assessment of hydroxypropyl methylcellulose as a food ingredient. Food and Chemical Toxicology. 2007; 45(12): 2341-51. doi: 10.1016/j.fct.2007.07.011. PMID: 17723258.

27) De Moura M, Avena Bustillos R, McHugh T, Krochta J, Mattoso L. Properties of novel hydroxypropyl methylcellulose films containing chitosan nanoparticles. Journal of food science. 2008; 73(7): 31-7. doi: 10.1111/j.1750-3841.2008.00872.x.

28) Sothornvit R, Krochta JM. Plasticizers in edible films and coatings. Innovations in food packaging. 2005: 403-33.

29) Zhou J, Wang S, Gunasekaran S. Preparation and characterization of whey protein film incorporated with TiO2 nanoparticles. Journal of food science. 2009; 74(7): 50-6. doi: 10.1111/j.1750-3841.2009.01270.x.

30) Shi L, Zhou J, Gunasekaran S. Low temperature fabrication of $\mathrm{ZnO}$-whey protein isolate nanocomposite. Materials Letters. 2008; 62(28): 4383-5. doi: 10.1016/j.matlet.2008.07.038.

31) Smith R. Biodegradable polymers for industrial applications: CRC Press; 2005.

32) Chen P, Zhang L. Interaction and properties of highly exfoliated soy protein/montmorillonite nanocomposites. Biomacromolecules. 2006; 7(6): 1700-6. doi: 10.1021/bm050924k.

33) Yu J, Cui G, Wei M, Huang J. Facile exfoliation of rectorite nanoplatelets in soy protein matrix and reinforced bionanocomposites thereof. Journal of Applied Polymer Science. 2007; 104(5): 3367-77. doi: 10.1002/app.25969.

34) Park HM, Li X, Jin CZ, Park CY, Cho WJ, Ha CS. Preparation and properties of biodegradable thermoplastic starch/clay hybrids. Macromolecular Materials and Engineering. 2002; 287(8): 553-8. doi: 10.1002/1439-2054.

35) Huang J, Xiao Y, Mya KY, Liu X, He C, Dai J, et al. Thermomechanical properties of polyimide-epoxy nanocomposites from cubic silsesquioxane epoxides. Journal of Materials Chemistry. 2004; 14(19): 285863. doi: 10.1039/B405427J.

36) Chen B, Evans JR. Thermoplastic starch-clay nanocomposites and their characteristics. Carbohydrate polymers. 2005; 61(4): 455-63. doi: 10.1016/j.carbpol.2005.06.020.

37) Yoon SY, Deng Y. Clay-starch composites and their application in papermaking. Journal of Applied Polymer Science. 2006; 100(2): 1032-8. doi: 10.1002/app.23007.

38) Cushen M, Kerry J, Morris M, Cruz-Romero M, Cummins E. Nanotechnologies in the food industryRecent developments, risks and regulation. Trends in Food Science \& Technology. 2012; 24(1): 30-46. doi: 10.1016/j.tifs.2011.10.006.

39) Rhim JW, Ng PK. Natural biopolymer-based nanocomposite films for packaging applications. Critical reviews in food science and nutrition. 2007; 47(4): 411-33. doi: 10.1080/10408390600846366.

40) Laskin AI, Bennett JW, Gadd GM. Advances in applied microbiology: Academic Press; 2003.

41) Cioffi N, Torsi L, Ditaranto N, Tantillo G, Ghibelli L, Sabbatini L, et al. Copper nanoparticle/polymer composites with antifungal and bacteriostatic properties. Chemistry of Materials. 2005; 17(21): 5255-62. doi: $10.1021 / \mathrm{cm} 0505244$.

42) Gu H, Ho P, Tong E, Wang L, Xu B. Presenting vancomycin on nanoparticles to enhance antimicrobial activities. Nano letters. 2003; 3(9): 1261-3. doi: 10.1021/n1034396z.

43) Rodriguez F, Sepulveda HM, Bruna J, Guarda A, Galotto MJ. Development of Cellulose Eco nanocomposites with Antimicrobial Properties Oriented for Food Packaging. Packaging Technology and Science. 2013; 26(3): 149-60. doi: 10.1002/pts.1980. 
44) Liau S, Read D, Pugh W, Furr J, Russell A. Interaction of silver nitrate with readily identifiable groups: relationship to the antibacterialaction of silver ions. Letters in applied microbiology. 1997; 25(4): 279-83. doi: 10.1046/j.1472-765X.1997.00219.x.

45) Sondi I, Salopek-Sondi B. Silver nanoparticles as antimicrobial agent: a case study on E. coli as a model for Gram-negative bacteria. Journal of colloid and interface science. 2004; 275(1): 177-82. doi: 10.1016/j.jcis.2004.02.012.

46) Li Q, Mahendra S, Lyon DY, Brunet L, Liga MV, Li D, et al. Antimicrobial nanomaterials for water disinfection and microbial control: potential applications and implications. Water Res. 2008; 42(18): 4591 602. doi: 10.1016/j.watres.2008.08.015. PMID: 18804836.

47) Morones JR, Elechiguerra JL, Camacho A, Holt K, Kouri JB, Ramirez JT, et al. The bactericidal effect of silver nanoparticles. Nanotechnology. 2005; 16(10): 2346-53. doi: 10.1088/0957-4484/16/10/059. PMID: 20818017.

48) Bouwmeester H, Dekkers S, Noordam MY, Hagens WI, Bulder AS, De Heer C, et al. Review of health safety aspects of nanotechnologies in food production. Regul Toxicol Pharmacol. 2009; 53(1): 52-62. doi: 10.1016/j.yrtph.2008.10.008. PMID: 19027049.

49) Liao F, Chen C, Subramanian V. Organic TFTs as gas sensors for electronic nose applications. Sensors and Actuators B: Chemical. 2005; 107(2): 849-55. doi: 10.1016/j.snb.2004.12.026.

50) De Azeredo H.M. Nanocomposites for food packaging applications. Food Research International. 2009; 42(9): 1240-53. doi: 10.1016/j.foodres.2009.03.019.

51) Koo B, Joseph H. Polymer Nanocomposites-Omar Manasreh. McGraw-Hill Professional Pub. $2006 ; 272$. doi: 10.1036/0071458212.

52) Echegoyen Y, Nerin C. Nanoparticle release from nano-silver antimicrobial food containers. Food chem toxicol. 2013; 62: 16-22. doi: 10.1016/j.fct.2013.08.014. PMID: 23954768.

53) Liu Jf, Yu Sj, Yin Yg, Chao Jb. Methods for separation, identification, characterization and quantification of silver nanoparticles. Trac Trends in Analytical Chemistry. 2012; 33: 95-106. doi: 10.1016/j.trac.2011.10.010.

54) Torres A, Guarda A, Moraga N, Romero J, Galotto MJ. Experimental and theoretical study of thermodynamics and transport properties of multilayer polymeric food packaging. European Food Research and Technology. 2012; 234(4): 713-22. doi: 10.1007/s00217-012-1683-1.

55) de Azeredo HM. Antimicrobial nanostructures in food packaging. Trends in Food Science \& Technology. 2013; 30(1): 56-69. doi: 10.1016/j.tifs.2012.11.006.

56) Song H, Li B, Lin QB, Wu HJ, Chen Y. Migration of silver from nanosilver-polyethylene composite packaging into food simulants. Food Additives \& Contaminants: Part A. 2011; 28(12): 1758-62. doi: 10.1080/19440049.2011.603705.

57) Schmidt B, Katiyar V, Plackett D, Larsen EH, Gerds N, Koch CB, et al. Migration of nanosized layered double hydroxide platelets from polylactide nanocomposite films. Food Addit Contam Part A Chem Anal Control Expo Risk Assess. 2011; 28(7): 956-66. doi: 10.1080/19440049.2011.572927. PMID: 21614708.

58) Bradley EL, Castle L, Chaudhry Q. Applications of nanomaterials in food packaging with a consideration of opportunities for developing countries. Trends in food science \& technology. 2011; 22(11): 604-10. doi: 10.1016/j.tifs.2011.01.002.

59) Busolo MA, Lagaron JM. Oxygen scavenging polyolefin nanocomposite films containing an iron modified kaolinite of interest in active food packaging applications. Innovative Food Science \& Emerging Technologies. 2012; 16: 211-7. doi: 10.1016/j.ifset.2012.06.008.

60) Hernandez Munoz P, Catala R, Gavara R. Simple method for the selection of the appropriate food simulant for the evaluation of a specific food/packaging interaction. Food Additives \& Contaminants. 2002; 19(1): 192-200. doi: 10.1080/02652030110069726.

61) Munro IC, Haighton LA, Lynch BS, Tafazoli S. Technological challenges of addressing new and more complex migrating products from novel food packaging materials. Food Additives and Contaminants. 2009; 26(12): 1534-46. doi: 10.1080/02652030902995277.

62) Thostenson ET, Li C, Chou TW. Nanocomposites in context. Composites Science and Technology. 2005; 65(3): 491-516. doi: 10.1016/j.compscitech.2004.11.003.

63) Sandoval BM. Perspectives on FDA's regulation of nanotechnology: emerging challenges and potential solutions. Comprehensive Reviews in Food Science and Food Safety. 2009; 8(4): 375-93. doi: 10.1111/j.1541-4337.2009.00088.x. 